\title{
Paediatricians Perceptions towards the Use of Sweetened Liquid Medications and its Relationship to Oral Health of Children
}

\author{
Srikala Bhandary ${ }^{1}$, Pooja M. R.2 ${ }^{2}$ Urvashi Ashwin Shetty ${ }^{3}$ \\ 1Reader, Department of Pedodontics and Preventive Dentistry, A.B. Shetty Memorial Institute of Dental Sciences, \\ NITTE (Deemed to be University), Mangalore, Karnataka, India. ${ }^{2}$ Student, A.B. Shetty Memorial Institute of Dental \\ Sciences, NITTE (Deemed to be University), Mangalore, Karnataka, India. ${ }^{3}$ Senior Lecturer, Department of Oral \\ Pathology, A.B Shetty Memorial Institute of Dental Sciences, NITTE (Deemed to be University), Mangalore, Karnataka, \\ India.
}

\section{ABSTRACT}

\section{BACKGROUND}

Oral liquid medications (syrups) are widely prescribed in children for better compliance. But, certain inactive agents that are added in paediatric liquid medications can injure the dental tissues and when used routinely over long time, it can make patients more susceptible to dental caries and dental erosion. Consumption during bedtime, low $\mathrm{pH}$, high viscosity, increased frequency of consumption, reduction in salivary flow and excessive sugar content lead to cariogenic and erosive potential of these drugs. We wanted to assess the perceptions of a group of paediatricians about the use of sweetened paediatric liquid medications and their erosive and cariogenic potentials.

\section{METHODS}

The study (questionnaire survey) was carried out in Mangalore. It included paediatricians from different health services, private and government hospitals, and private clinics. Questionnaires were given and collected the same day.

\section{RESULTS}

$40(44 \%)$ paediatricians revealed considerable awareness regarding the association between the paediatric medicines and dental decay, which was not observed for the association between paediatric medicines and dental erosion which was only 17 (18.7\%).

\section{CONCLUSIONS}

There is a need to create awareness amongst these professionals to ensure and encourage practicing of oral hygiene instructions for their paediatric patients, postusage of sucrose containing drugs, because majority of the paediatricians recognized the positive association between sucrose containing liquid medication and dental caries. An added training should be given to these professionals to motivate their patients to follow oral hygiene instructions after consumption of sweetened liquid medications.

\section{KEY WORDS}

Oral Health, Paediatricians, Oral Liquid Medications, Cariogenic, Erosion
Corresponding Author: Dr. Urvashi Ashwin Shetty, Senior Lecturer, Department of Oral Pathology, A.B Shetty Memorial Institute of Dental Sciences, NITTE (Deemed to be University), Deralakatte, Mangalore-575018,

Karnataka, India.

E-mail: docsrikala@gmail.com urvashishetty10@gmail.com

DOI: $10.14260 / \mathrm{jemds} / 2019 / 667$

Financial or Other Competing Interests: None.

How to Cite This Article:

Bhandary S, Pooja MR, Shetty UA. Paediatricians Perceptions Towards the Use of Sweetened Liquid Medications and its Relationship to Oral Health of Children. J. Evolution Med. Dent. Sci. 2019;8(41): 3070-3073,

DOI:
Submission 22-07-2019,

Peer Review 25-09-2019,

Acceptance 01-10-2019,

Published 14-10-2019. 


\section{BACKGROUND}

An extremely important aspect for children's general health, growth and development is their oral health. Dental caries is the most common and prevalent infectious disease in the oral cavity. It is a dynamic disease involving the calcified tissues of the teeth and requires the presence of bacterial plaque, a dietary fermentable carbohydrate which results in acid production and subsequent demineralisation of the tooth surface. The $\mathrm{pH}$ drops causing demineralization of tooth structure as the concentration of organic acids increases in the inner layer of plaque. In children to ease compliance sweetened liquid oral medications are used widely. However, dental tissues can be injured due to certain inactive agents that are added to these medicaments. ${ }^{1,2}$ When these drugs are used routinely over long periods, it can make patients more susceptible to dental caries and dental erosion. This concern is ignored because the primary medical problem covers up the less noticeable aspects of the health of the child. Under such conditions, parent's chief focus is the medical problem and hence poor oral hygiene can be anticipated as the child's routine is altered. Increased frequency of intake, low $\mathrm{pH}$, high viscosity, consumption during bedtime, reduction in salivary flow and excessive sugar content leads to the cariogenic and erosive potential of these drugs. ${ }^{3}$

As fermentable carbohydrates play an important role in the carious process, the effect of long duration consumption of such medicines is considered as a concern to dental health. Numerous studies showed that the presence of sugars in liquid medicines plays a significant role in the aetiology of dental caries in children. ${ }^{4}$ To promote an agreeable taste, sugars are added to medicines to increase compliance and also acts as a bulking agent, preservative, and as well as an antioxidant. ${ }^{5}$

The source of dental erosion is acid, that acts on a susceptible tooth which may be intrinsic or extrinsic. ${ }^{6}$ Preparations used for drug dispersion are often acidic. Certain drugs are acidic because of their high titrable acidity and low $\mathrm{pH}$ and which makes them an extrinsic agent, causing dental erosive lesions on teeth, particularly if ingested frequently.1,2 The latest change to eliminate sugary medicines to decrease the dental caries risk has been accepted by dentists, but the fear is that the shift to medicines that are sugar-free might themselves damage teeth. Addition of weak acids to certain products might be required to improve their taste and preparation properties to reformulate medicines without sugars. The concern is, will this cause an increase in dental erosion, i.e., did we interchange one problem (Dental caries) for another (Dental erosion)?

Paediatricians provide anticipatory guidance on oral wellbeing issues as they are among the first few to ascertain interaction with families of the child patients and also access frequently to children during their regular visits. ${ }^{7}$ These professionals are, therefore, the main sources of paediatric medicaments, as they can influence the use and supply of such medicines. Similar studies conducted by Duward and Thou ${ }^{3}$ revealed that the damage caused by liquid medicines with regular consumption is not a well-known fact to the paediatricians.

Hence, the study was aimed at assessing the paediatricians' perceptions towards the use of sweetened paediatric liquid medicines and their cariogenic and erosive potentials.

\section{METHODS}

The present study (cross sectional Questionnaire survey) was carried out in Mangalore Karnataka. Based on the previous studies, considering $\mathrm{P}$ at $51 \%$, confidence level set at $95 \%$, power of study $80 \%$ and relative precision of $20 \%$ of $\mathrm{P}$, the sample size was estimated to be 96 rounded off to 100 . Hence A total of 117 questionnaires were distributed personally to paediatricians from different health services, private and government hospitals and private clinics and 93 filled questionnaires were obtained. Questionnaires were given and collected the same day. 24 paediatricians did not respond to the study due to their busy schedule. Reliability and validity of the questionnaire was checked by conducting a pilot study among 10 paediatricians which are included in this study. All paediatricians who accepted to participate in the study were included after obtaining informed consent from them, and their anonymity was secured by coding (Instead of names numbers were used) the returned questionnaire. Ethical clearance was received from the institutional ethical committee.

\section{Statistical Analysis}

The data collected was entered into Microsoft excel spread sheet and analysed by SPSS 11.0. Descriptive analysis was used in the present study and results were expressed as frequency and percentages.

\section{RESULTS}

117 Questionnaires were delivered, of which 93 questionnaires were answered and returned. Paediatricians aged between 25-65 years participated in the study, among which $58.2 \%$ were males, and $41.8 \%$ were female doctors. $82.4 \%$ of paediatricians said they treated only child patient, and $17.6 \%$ treated both children and adult. Out of which $16.5 \%$ work in rural areas, $79.1 \%$ in urban and $4.4 \%$ in semiurban areas. When asked about the mode of administration of the drug preferred, $91.2 \%$ preferred oral, $1.1 \%$ preferred intramuscular, and $7.7 \%$ preferred other routes.

When asked whether paediatric syrup can cause dental caries, $44 \%$ of the paediatricians said yes, and $53.8 \%$ said no, and $2.2 \%$ said they did not know. When asked about the type of liquid paediatric medicines they preferred to prescribe, $75.8 \%$ said sweetened $7.7 \%$ said non-sweetened and $15.4 \%$ preferred sugar substituted medicines. When asked whether oral hygiene is important for children, $96.7 \%$ said yes, and only $3.3 \%$ said no. When asked whether oral hygiene instructions are recommended after medicine intake at night, $49.5 \%$ said yes, and $50.5 \%$ said no. $30.8 \%$ said paediatric medicines are acidic, $44 \%$ said no, and $25.3 \%$ said they do not know. $68.1 \%$ said paediatric medicines does not cause tooth structure defects like wear/erosion, $18.7 \%$ said it causes and $13.2 \%$ said they do not know. When asked, whether children using inhalers for bronchial asthma have any tooth structure defects $19.8 \%$ said Yes, $76.9 \%$ said no and 3.3\% said don't know. Does 
lack of oral hygiene after medicine intake cause dental caries, $81.3 \%$ said yes, $13.25 \%$ said no and $5.5 \%$ said don't know. Does mode and frequency of medicine intake cause dental decay/ alterations, $44 \%$ of paediatricians said yes, $50.5 \%$ said no and $5.5 \%$ said they do not know. When asked their opinion, whether dental decay can be caused by reduced salivary flow due to some drugs, $58.2 \%$ said yes, $36.3 \%$ said no and $5.5 \%$ said they don't know. When asked about their opinion whether chronic use of liquid paediatric medicine causes dental decay/ alterations, $72.5 \%$ said yes, $25.3 \%$ said no, and $2.2 \%$ said don't know as shown in (Table 1 )

\begin{tabular}{|c|c|c|}
\hline & & $\begin{array}{c}\text { Number } \\
(\%)\end{array}$ \\
\hline Can liquid paediatric syrups cause dental caries & $\begin{array}{c}\text { Yes } \\
\text { No } \\
\text { Don't know }\end{array}$ & $\begin{array}{c}40(44) \\
49(53.8) \\
2(2.2)\end{array}$ \\
\hline $\begin{array}{l}\text { What type of liquid paediatric medicines do you } \\
\text { prefer or prescribe }\end{array}$ & $\begin{array}{l}\text { sweetened } \\
\text { Non- } \\
\text { sweetened } \\
\text { Sugar } \\
\text { substituted }\end{array}$ & $\begin{array}{c}69(75.8) \\
7(7.7) \\
14(15.4)\end{array}$ \\
\hline $\begin{array}{l}\text { Do you feel oral hygiene is important for } \\
\text { children }\end{array}$ & $\begin{array}{l}\text { Yes } \\
\text { No }\end{array}$ & $\begin{array}{c}88(96.7) \\
3(3.3)\end{array}$ \\
\hline $\begin{array}{l}\text { Do you advise oral hygiene instructions intake of } \\
\text { medicine at night }\end{array}$ & $\begin{array}{l}\text { Yes } \\
\text { No }\end{array}$ & $\begin{array}{l}45(49.5) \\
46(50.5)\end{array}$ \\
\hline Are paediatric medicines acidic & $\begin{array}{c}\text { Yes } \\
\text { No } \\
\text { Don't know }\end{array}$ & $\begin{array}{c}28(30.8) \\
40(44) \\
23(25.3)\end{array}$ \\
\hline $\begin{array}{l}\text { Do paediatric medicines cause tooth structure } \\
\text { defects like wear/ erosion }\end{array}$ & $\begin{array}{l}\text { No } \\
\text { Yes } \\
\text { Don't know }\end{array}$ & $\begin{array}{l}62(68.1) \\
17(18.7) \\
12(13.2)\end{array}$ \\
\hline $\begin{array}{l}\text { In your opinion, children using inhalers for } \\
\text { bronchial asthma have any tooth structure } \\
\text { defects }\end{array}$ & $\begin{array}{c}\text { Yes } \\
\text { No } \\
\text { Don't know }\end{array}$ & $\begin{array}{c}18(19.8) \\
70(76.9) \\
3(3.3)\end{array}$ \\
\hline $\begin{array}{l}\text { Do you feel, lack of oral hygiene after medicine } \\
\text { intake can cause dental caries }\end{array}$ & $\begin{array}{c}\text { Yes } \\
\text { No } \\
\text { Don't know }\end{array}$ & $\begin{array}{c}74(81.3) \\
12(13.2) \\
5(5.5)\end{array}$ \\
\hline $\begin{array}{l}\text { Do you feel that mode and frequency of medicine } \\
\text { intake can cause dental decay/ alterations }\end{array}$ & $\begin{array}{c}\text { Yes } \\
\text { No } \\
\text { Don't know }\end{array}$ & $\begin{array}{c}40(44) \\
46(50.5) \\
5(5.5)\end{array}$ \\
\hline $\begin{array}{l}\text { In your opinion, can salivary flow decrease } \\
\text { caused by some drugs cause dental decay }\end{array}$ & $\begin{array}{c}\text { Yes } \\
\text { No } \\
\text { Don't know }\end{array}$ & $\begin{array}{c}53(58.2) \\
33(36.3) \\
5(5.5)\end{array}$ \\
\hline $\begin{array}{l}\text { In your opinion can chronic use of paediatric } \\
\text { liquid medicine cause dental decay/ alterations }\end{array}$ & $\begin{array}{c}\text { Yes } \\
\text { No } \\
\text { Don't know }\end{array}$ & $\begin{array}{c}66(72.5) \\
23(25.3) \\
2(2.2)\end{array}$ \\
\hline
\end{tabular}

\section{DISCUSSION}

Bioavailability, stability, palatability, and improvement in appearance are some of the purposes of pharmaceutical products. Such agents are adjuvants that are considered passive, and they do not have a synergic effect on the proposed action of the therapeutically active ingredients. ${ }^{8}$ The most arduous task for the paediatricians in the treatment of paediatric patients is the observance of the patient to a specific medication routine and ensuring that the use of pleasant tasting liquid medicines have aided in the drug administration. ${ }^{6}$ Roberts and Roberts in 1979, first documented the detrimental effects of sugar based liquid oral medicines on dental health. But until 1980, the term medication caries was not used. ${ }^{9}$ These sugar-based preparations are concern to paediatricians as they provide a substrate for plaque microorganisms through the day when they are used abundantly. Large amount of sugars, especially sucrose in the formulation of cough syrups, antibiotic syrups, lozenges, vitamin preparations and others are used by the pharmaceutical industries. The term sugar includes all monosaccharides and disaccharides and the most common of which are glucose, fructose, sucrose, maltose and lactose. The widely used sugar is sucrose due to its properties as a solvent, antioxidant, preservative and thickening agent and also due to its low cost. It is due to its pleasant sweetish taste that encourages medicine acceptance by children. ${ }^{10}$

People are largely ignorant of the damage caused by these medicines when used regularly. These can aggravate abnormalities in children's dentition. ${ }^{11}$ Thus, paediatricians are in the best position to give guidance to parents regarding oral health. ${ }^{12}$ But problems faced by the paediatrician to promote oral health is due to lack of awareness with oral health issues largely leaves the paediatrician in trouble in promoting awareness about the oral health issues and its reflection on the systemic health..$^{13}$ The results of this study are certainly reassuring and indicate the need for a reasonable understanding of the problem among the paediatricians, as most of them agreed that paediatric syrups might lead to dental problems.

Sweetened liquid medications, when used on a daily basis, poses a risk to dental health.3,4 The results of our study revealed that only $44 \%$ of the paediatricians believed that dental decay can be caused due to these sugary syrups, while the possibility of the use of sugar substitutes in paediatric medicines was known to only about $15.4 \%$ of them. This indeed gave a positive perception. Studies conducted by Duward and Thou $^{3}$ on dental caries and sugar containing medicines revealed that paediatricians are not fully aware of the damage caused by regular consumption of liquid medicines on children's teeth. Further they recommended that awareness of the danger posed by these medications should be promoted among prescribers, pharmacists, manufacturers, regulatory authorities and the public in order to bring about increased availability and use of sugar free liquid medicines.

The presence of sucrose in the medicines has a masking effect on the unpleasant flavour of the active ingredients. However, sucrose is well known as the arch criminal of dental caries. $^{3-5}$ Certain studies done in Brazil established the fact that the principal sweetener used in numerous liquid medications is sucrose.12,14 In this study, although many paediatricians (75.8\%) advised sweetened medicines, all of them did not advocate adequate oral hygiene maintenance protocols following intake of the same $(50.5 \%)$. Even though paediatricians $(96.7 \%)$ believed that oral hygiene is important for children, and $81.3 \%$ of them believed that lack of oral hygiene after taking sweetened medication can cause dental caries, only $49.5 \%$ recommended oral hygiene after intake of medicines These findings are in agreement with a study conducted by Pierro et al, where he revealed that oral hygiene instructions were not given to the patients by paediatricians after intake of such medicines.

Medication when acidic reduces the hardness of enamel and also influences its roughness. Studies were done in vitro, have already confirmed the erosive potential of these syrups. Brazilian studies verified that most paediatric medicines used were known to be responsible for the dissolution of the enamel having an endogenous $\mathrm{pH}$ value, which is lower than the critical pH of 5.5. In this study, $44 \%$ of the paediatricians were 
of the view that these medicines are not acidic and do not cause dental wear $(68.1 \%)$ while $30.8 \%$ of them agreed to it being acidic and $18.7 \%$ said they could cause dental wear. Similar study conducted by Costa CC, Almeida ICS, Costa Filho $\mathrm{LC}^{1}$ on the erosive effect of an antihistamine containing syrup revealed that these syrups can reduce the hardness of the enamel of primary teeth and that the use of fluoride containing dentifrice was able to diminish this erosive effect. However, $58.2 \%$ of them agreed to say a reduction in salivary flow caused by some drugs causes decay of teeth and $36.3 \%$ disagreed. When asked about the chronic usage of the liquid sweetened paediatric medication causing dental decay, $72.5 \%$ they agreed and $25.3 \%$ of them disagreed. This disorder was justified with a change in oral $\mathrm{pH}$, high viscosity, and acidity of the medicine. The results of this questionnaire could indicate the fact that paediatrician's response to this study may not represent the actual experiences of the patients and moreover, respondents of this study might have overemphasized their attitudes about oral health to provide a more agreeable answer, which may be a flaw in the same.

Recommendations for reducing tooth destruction caused by regular use of liquid medications-

1. Medication can be taken in the form of a tablet when possible.

2. Rinsing mouth after every dose of sweetened syrups.

3. Using sugar-free chewing gums after taking medicines.

4. Home and dental office fluoride applications.

5. Liquid medicines to be taken with meals and not in between meals.

6. Avoid taking a medication just before bedtime.

7. Seeking regular preventive dental care.

8. Try to use sugar-free medication.

9. Regular tooth brushing with fluoridated toothpaste twice daily.

\section{CONCLUSIONS}

This study concluded that the paediatricians had a substantial understanding regarding the association between sweetened paediatric syrups and dental decay, which was not observed for the association between the paediatric medicines and dental erosion. This study has raised the need for creating awareness amongst these professionals to ensure and encourage to suggest oral hygiene instructions to their paediatric patients, post-usage of sucrose containing drugs because majority of the paediatricians recognized the positive association between sucrose containing liquid medication and dental caries. Also, to provide a complete overall health to our patients, it would be worthwhile to have more interactions between the paediatric dentists and the paediatricians.

\section{REFERENCES}

[1] Costa CC, Almeida ICS, Costa FLC. Erosive effect of an antihistamine-containing syrup on primary enamel and its reduction by fluoride dentifrice. Int J Paediatr Dent 2006;16(3):174-80.

[2] Nunn JH, Ng SK, Sharkey I, et al. The dental implications of chronic use of acidic medicines in medically compromised children. Pharm World Sci 2001;23(3):118-9.

[3] Durward C, Thou T. Dental caries and sugar-containing liquid medicines for children in New Zealand. N Z Dent J 1997;93(414):124-9.

[4] Bigeard L. The role of medication and sugars in pediatric dental patients. Dent Clin North Am 2000;44(3):443-56.

[5] Shaw L, Glenwright HD. The role of medications in dental caries formation: the need for sugar-free medication for children. Paediatrician 1989;16(3-4):153-5.

[6] Linnett V, Seow WK. Dental erosion in children: a literature review. Pediatr Dent 2001;23(1):37-43.

[7] Krol DM. Educating pediatricians on children's oral health: past, present and future. Pediatrics 2004;113(5):e487-e92.

[8] American Academy of Pediatrics Committee on Drugs. "Inactive" ingredients in pharmaceutical products: update (subject review). Paediatrics 1997;99(2):268-78.

[9] Roberts IF, Roberts GJ. Relation between medicines sweetened with sucrose and dental disease. Br Med J 1979;2(6181):14-6.

[10] Moynihan PJ. Update on the nomenclature of carbohydrates and their dental effects. J Dent 1998;26(3):209-18.

[11] Evans DJ, Howe D, Maguire A, et al. Development and evaluation of a sugar-free medicines campaign in North Eat England: Analysis of findings from questionnaires. Community Dent Health 1999;16(3):131-7.

[12] De Silva PVS, Barcelos R, Maria LC, et al. Paediatrician's perception of the use of antibiotics and dental caries - a Preliminary Study. J Public Health Dent 2004;64(4):2448.

[13] Lewis CW, Grossman DC, Domoto PK, et al. The role of the paediatrician in the oral health of children: a national survey. Paediatrics 2000;106(6):E84.

[14] Lima KT, Ameida ICS, Senna ETL. Medicamentos Pediatricos-agentesedulcorantesep H. J Bras Odontopediatrodontol Bebe 2000;3:457-63. 